\title{
A QUALIDADE DE ÁGUA COMO INDICADOR DE USO E OCUPAÇÃO DO SOLO: BACIA DO GAMA - DISTRITO FEDERAL
}

\author{
Luiz Henrique Amorim Moura*, Geraldo Resende Boaventura e Marcelo Pedrosa Pinelli
}

Instituto de Geociências, Universidade de Brasília, 70910-900 Brasília - DF, Brasil

Recebido em 4/2/09; aceito em 21/7/09; publicado na web em 25/11/09

\begin{abstract}
THE WATER QUALITY AS AN INDICATOR OF LAND USE AND OCCUPATION: GAMA BASIN-DF. The spread of Brasília isn't accompanied by correct support of land occupation, situation that is reflected in water quality. Under the optics of land use and occupation, working with multivariate statistics as main tool, water physical and chemical quality of Gama Catchment were assessed. During two years samples were collected and analyzed for 24 parameters. The statistical analysis showed the influence of civil buildings, agricultural activities and the best statistical parameters to a quickly assessment: nitrate, ammonia, suspended solids and aluminium.
\end{abstract}

Keywords: Gama River; water geochemistry; multivariate statistics.

\section{INTRODUÇÃO}

Uma bacia hidrográfica compreende diversos tributários que convergem para um curso principal, carregando uma boa quantidade de material de origem natural e antrópica, se estiver inserido em um núcleo urbano e/ou agrícola, cujas águas têm suas características modificadas. A qualidade de água em qualquer ponto de um rio/ tributário reflete a influência da geologia, vegetação, solos, clima e, sobretudo, do homem. ${ }^{1}$ No caso da influência antrópica, os rios assimilam materiais provenientes de esgotos, atividades agrícolas, indústrias e construção civil, ou seja, de qualquer atividade em que as condições naturais da bacia são alteradas em função da expansão urbana. Tais fatores podem ser atenuados ou mascarados pelos processos naturais como, por exemplo, as chuvas, variações climáticas e o escoamento superficial. ${ }^{1}$

Brasília é um conjunto de núcleos urbanos que retrata bem a relação entre a construção/ampliação da capital federal e os recursos hídricos, sejam eles superficiais ou subterrâneos. Estudos realizados em duas importantes bacias hidrográficas do Distrito Federal, a Bacia do Rio Descoberto $^{2}$ e a Bacia do São Bartolomeu ${ }^{3}$ demonstraram a influência da ocupação urbana nessas bacias, caracterizada pelos efluentes domésticos e atividades agrícolas. As mesmas influências também foram verificadas para as águas subterrâneas. ${ }^{4}$ Para um local como Brasília, onde a disponibilidade hídrica, definida em função da regularidade na distribuição de água e da densidade demográfica, é a terceira pior do país, ${ }^{5}$ esses recursos merecem uma atenção especial da sociedade.

Uma vez que os rios são os principais fornecedores de água para a população, indústrias e agricultura é conveniente identificar e prevenir as principais fontes de poluição, bem como obter dados para efetiva gestão. A avaliação dos dados de qualidade de água envolve uma grande quantidade de variáveis, cuja interpretação se torna difícil e dispendiosa. ${ }^{1}$ Uma das diversas técnicas de análise de dados é a análise multivariada, que corresponde a um grupo de técnicas estatísticas que buscam relacionar as variáveis pesquisadas. ${ }^{6} \mathrm{~A}$ complexidade matemática por trás desses métodos é facilmente ocultada nos softwares estatísticos, ${ }^{7}$ cujas técnicas computacionais vêm cumprindo o papel de reduzir a grande quantidade de dados sem a perda de informação, bem como o estudo da associação e correlação entre as variáveis. ${ }^{8,9}$

O objetivo desse trabalho foi a avaliação da qualidade de água, restringindo apenas no aspecto composicional, na bacia do Ribeirão

*e-mail: lhamoura@yahoo.com.br do Gama e do Córrego do Cedro, determinando as possíveis fontes de alteração e diferenciando os impactos relacionados à ocupação humana dos processos naturais influenciados pela geologia regional. A análise estatística multivariada foi a principal ferramenta empregada para interpretação da qualidade de água e, também, a discriminação dos parâmetros mais representativos, resultando em um modelo de avaliação de qualidade de água a partir da interface água influenciada pelos processos naturais da água influenciada pelos processos antrópicos.

\section{PARTE EXPERIMENTAL}

\section{Localização e caracterização da área}

A área de estudo está localizada na Bacia Hidrográfica do Gama (Brasília, DF), que por sua vez integra a grande Bacia do Lago Paranoá. As bacias hidrográficas do Lago Paranoá e Riacho Fundo, ambas pertencentes à grande Bacia do Lago Paranoá, que abrigam o Plano Piloto e as cidades satélites do Guará e Núcleo Bandeirante, respectivamente, são limítrofes à Bacia do Gama, além das grandes bacias do Rio Corumbá, a sudoeste, e do Rio São Bartolomeu, a leste, cujas águas escoam em direção ao Rio Paraná. Os corpos hídricos pesquisados compreendem o curso médio/final do Ribeirão do Gama e de todo o curso do Córrego Cedro. Esta área ocupa 31,9 km² (dos 145,6 $\mathrm{km}^{2}$ da Bacia do Gama) e está situada entre as coordenadas UTM, zona 23L, $183860 \mathrm{~m}$ e $191330 \mathrm{~m}$ (Leste) e $8242800 \mathrm{~m}$ e $8239700 \mathrm{~m}$ (Norte). Próximas a esses dois corpos hídricos estão a segunda pista do Aeroporto Internacional de Brasília, as quadras 14, 19, 21, 23, 24 e 25 do Setor de Mansões ParkWay (SMPW), o Núcleo Rural Vargem Bonita (NRVB), o Jardim Botânico e a Reserva Ecológica do Instituto Brasileiro de Geografia e Estatística (IBGE) integrando a região administrativa Lago Sul. ${ }^{10}$

O Ribeirão do Gama nasce na Mata do Catetinho e ao longo dos seus $14 \mathrm{~km}$ de curso recebe águas dos Córregos do Mato Seco, do Cedro e Taquara, desaguando no Lago Paranoá com uma vazão média de $1,85 \mathrm{~m}^{3} / \mathrm{s}$. Quando nasce, o Ribeirão do Gama já tem suas águas influenciadas pelo núcleo habitacional SMPW e adiante é represado. Juntamente com o Córrego Mato Seco, afluente da margem esquerda, além da influência habitacional, passa a ser afetado pelo NRVB, importante pólo de abastecimento de hortifrutigranjeiros em Brasília. O Córrego Taquara, afluente direito, contribui com águas preservadas, uma vez que nasce na Reserva Ecológica do IBGE. 
Nos cursos médio e final, o ribeirão, no lado direito, possui terrenos preservados em função do Jardim Botânico de Brasília e, na margem esquerda, o SMPW e as águas do Córrego Cedro.

A Bacia Hidrográfica do Gama formou-se sobre as rochas do Grupo Paranoá (Idade Meso/Neoproterozoíca) especificamente nas unidades Ardósia (A) e Metarritmito Arenoso (R3). ${ }^{10}$ Além dessa sequência areno-argilosa, o Grupo Paranoá comporta as unidades Siltito (S), Quartzito (Q3), Metarritmito Silto-Argilosos (R4) e a Psamo-Pelito-Carbonatada (PPC). À oeste do Grupo Paranoá afloram as rochas do Grupo Araxá (Neoproterozoíco) e a leste o Grupo Canastra (Mesoproterozíco), ambos presentes no DF. Quanto à cobertura vegetal ocorrem seis fitofisionomias: ${ }^{11}$ Mata de Galeria, Cerradão, Cerrado, Vereda, Campo Sujo e Campo Limpo. Os solos presentes na região são os hidromórficos, cambissolos e latossolos, ${ }^{10}$ sendo o último o mais predominante.

Em relação ao clima o DF possui dois períodos climáticos bem distintos, típicos da região de cerrado, evidenciados pela alta taxa de precipitação no verão ( $250 \mathrm{~mm}$ em dezembro) com temperatura média de $22{ }^{\circ} \mathrm{C}$ e um período extremamente seco no inverno $(9 \mathrm{~mm}$ em junho) com média de temperatura de $18{ }^{\circ} \mathrm{C}$. Espacialmente, a variação na precipitação segue uma tendência decrescente de oeste para leste. Anualmente são esperados cerca de $1500 \mathrm{~mm}$ de chuva em Brasília. ${ }^{10}$

\section{Amostragem e métodos analíticos}

$\mathrm{Na}$ ampliação do Aeroporto Internacional de Brasília foi feito um estudo da qualidade de água, que compreendeu os anos de 2003, 2004 e 2005, de modo que toda a alteração no Córrego Cedro fosse detectada. As amostras de água foram coletadas em cinco pontos, sendo dois deles no curso principal da bacia e os outros três no Córrego Cedro, mensalmente entre novembro de 2003 e outubro de 2005, totalizando 115 amostras. As coletas de amostras foram feitas em garrafas de polietileno de $2 \mathrm{~L}$, previamente lavadas em ácido clorídrico 1:3 e água destilada, no meio do curso dos rios, numa profundidade entre 20 e $30 \mathrm{~cm}$, sem auxílio de barco.

No curso principal da Bacia do Gama estão os pontos 1 e 5, entre esses está o Córrego do Cedro, com os pontos 2, 3 e 4. Os pontos 1 e 5 estão a montante e jusante do ponto de união do Ribeirão do Gama e do Córrego do Cedro, sendo o ponto 1 situado na quadra 24 do SMPW, caracterizado por solo exposto, construção civil e mata de galeria preservada. $\mathrm{O}$ ponto 5 também possui mata de galeria preservada e registra se a mudança na qualidade de água nos pontos anteriores permanece após a mistura das águas.

Nos pontos localizados no Córrego do Cedro, na margem esquerda, está o sítio aeroportuário, na margem direita o SMPW. Os pontos 2 e 3 possuem em comum a presença de solo hidromórfico, sendo que no ponto 3 , em épocas chuvosas, em função da subida do lençol freático, os limites do córrego são ampliados. A proximidade com a ocupação urbana e sítio aeroportuário cresce do ponto 2 para o 4, sendo que no último a região é invadida por casebres, onde o saneamento para coleta de esgoto é ausente, sendo utilizadas fossas negras, e a vegetação é praticamente ausente.

\section{Métodos analíticos}

Nas amostras de água foram determinados: $\mathrm{pH}$, temperatura (TEMP), condutividade (COND), oxigênio dissolvido (OD), alcalinidade (ALCA), turbidez (TUR), cor, dureza (DUR), nitrato (NO3), nitrito (NO2), amônia (NH4), sólidos em suspensão (SS), sólidos dissolvidos (SD), sólidos totais (ST), demanda bioquímica de oxigênio (DBO), demanda química de oxigênio (DQO) e os elementos $\mathrm{Ca}, \mathrm{Mg}, \mathrm{Fe}, \mathrm{Al}, \mathrm{Si}, \mathrm{P}, \mathrm{Na}$ e K.
Do ponto de vista físico-químico adotaram-se as técnicas de análise e, também, de coleta, segundo o Standard Methods for the Examination of Water and Wastewater (American Public Health Association $)^{12}$ através do uso dos equipamentos: multiparâmetro HORIBA Water Checker U-40 (campo) e o espectrofotômetro UVVisível HACH-DR 2000 (laboratório).

Em campo foram registrados $\mathrm{pH}$, condutividade, total de sólidos dissolvidos (TDS), oxigênio dissolvido e temperatura. A parte experimental foi realizada no Laboratório de Geoquímica do Instituto de Geociências da Universidade de Brasília. Nitrato, nitrito, amônia, cor e turbidez foram determinados através do espectrofotômetro UV Visível. A volumetria foi técnica empregada para determinação da alcalinidade e DQO. O sólido em suspensão foi determinado após filtragem das amostras utilizando membranas de celulose $(0,45 \mu \mathrm{m})$ Millipore. Os elementos $\mathrm{Ca}, \mathrm{Mg}, \mathrm{Fe}, \mathrm{Al}, \mathrm{Si}$ e $\mathrm{P}$ foram determinados através do espectrômetro de emissão atômica com plasma indutivamente acoplado (ICP/AES), modelo FVM03 da Spectral Analytical Instruments, e $\mathrm{Na}$ e K, pelo espectrofotômetro de absorção atômica (AAS), modelo 603 de duplo feixe da Perkin Elmer.

\section{Tratamento dos dados e os métodos estatísticos multivariados}

Inicialmente a matriz de dados originais foi submetida à Análise de Principais Componentes (PCA, Principal Component Analysis), no modo Q e R. A PCA é uma técnica usada para reduzir a dimensão de problemas multivariados e detectar os parâmetros mais significativos que descrevam o conjunto de dados com a mínima perda dos dados originais..$^{1,9,13,14}$ No modo $\mathrm{R}$, os parâmetros de qualidade de água mais representativos foram extraídos e, no modo Q, a tabela de 115 observações por 24 variáveis foi reescrita usando apenas 8 variáveis.

Para reunir os parâmetros e observações semelhantes e separar os mais distantes, recorreu-se à análise de agrupamento..$^{1,6,8}$ Dentre as diversas técnicas de análise de agrupamento (CA, Cluster Analysis), a hierárquica e a não-hierárquica (K-médias) foram usadas neste trabalho. O agrupamento hierárquico unifica os parâmetros em classes ou grupos, cuja variação das observações é semelhante. ${ }^{14}$ Com K-médias é possível determinar o número de grupos/classes (clusters) a serem diferenciados, com a maior distinção possível entre eles. ${ }^{6,15}$

Para representar os dados de diversas ordens de grandeza e unidades específicas de medida, em valores compatíveis, passíveis de comparação, recorreu-se à técnica da padronização. ${ }^{7}$ Os novos valores são compatíveis com uma distribuição com média zero e desvio padrão 1 .

Para fornecer o modelo matemático de avaliação de qualidade de água para os dois corpos hídricos, empregou-se a análise discriminante (DA, Discriminant Analysis). A discriminação encontra uma combinação linear usando os parâmetros para diferenciar duas condições de qualidade de água. ${ }^{16}$ A DA pode ser efetuada de dois modos, que variam a maneira de como as variáveis são selecionadas para a análise. No modo direto ou padrão (standard) as variáveis independentes entram na análise ao mesmo tempo. O modo direto é apropriado quando o pesquisador deseja incluir todas as variáveis independentes na análise e pouco interessam os resultados intermediários. Os resultados intermediários compõem o modo stepwise e incluem cálculos com objetivo de determinar as melhores variáveis discriminantes entre os grupos.

\section{RESULTADOS E DISCUSSÃO}

Na Tabela 1 estão relacionadas as médias aritméticas e os desvios padrões dos parâmetros determinados, bem como a vazão, nos cinco pontos amostrados. 
Tabela 1. Médias e desvios padrões das 24 variáveis, mais a vazão, nos cinco pontos na Bacia do Gama

\begin{tabular}{|c|c|c|c|c|c|c|c|c|c|c|c|}
\hline & Unidade & $\begin{array}{l}\text { Ponto } 1 \\
\text { Média }\end{array}$ & Desvio & $\begin{array}{l}\text { Ponto } 2 \\
\text { Média }\end{array}$ & Desvio & $\begin{array}{c}\text { Ponto } 3 \\
\text { Média }\end{array}$ & Desvio & $\begin{array}{c}\text { Ponto } 4 \\
\text { Média }\end{array}$ & Desvio & $\begin{array}{c}\text { Ponto } 5 \\
\text { Média }\end{array}$ & Desvio \\
\hline $\mathrm{pH}$ & - & 6,18 & 0,54 & 5,98 & 0,70 & 5,81 & 0,57 & 5,89 & 0,55 & 6,12 & 0,34 \\
\hline Temp & ${ }^{\circ} \mathrm{C}$ & 20,66 & 1,33 & 21,02 & 1,18 & 20,60 & 1,53 & 20,96 & 1,24 & 20,14 & 1,28 \\
\hline Cond & $\mu \mathrm{S} / \mathrm{cm}$ & 20,4 & 12,3 & 18,2 & 12,2 & 20,2 & 17,2 & 15,8 & 10,2 & 21,1 & 15,2 \\
\hline OD & $\mathrm{mg} / \mathrm{L}$ & 7,14 & 0,73 & 5,96 & 0,60 & 5,84 & 1,36 & 6,45 & 0,92 & 6,71 & 0,91 \\
\hline Alca & $\begin{array}{c}\mathrm{mg} / \mathrm{L} \\
\mathrm{CaCO}_{3}\end{array}$ & 13,7 & 6,3 & 11,5 & 5,1 & 10,2 & 5,3 & 9,9 & 3,7 & 12,1 & 5,5 \\
\hline Tur & $\mathrm{uT}$ & 12,7 & 9,3 & 5,7 & 3,0 & 11,3 & 11,5 & 11,1 & 8,0 & 18,0 & 12,8 \\
\hline Cor & $\mathrm{uH}$ & 13,6 & 15,5 & 12,6 & 16,9 & 13,1 & 16,4 & 10,8 & 7,2 & 12,6 & 9,4 \\
\hline Dur & $\begin{array}{c}\mathrm{mg} / \mathrm{L} \\
\mathrm{CaCO}_{3}\end{array}$ & 6,16 & 2,10 & 5,54 & 1,77 & 4,56 & 1,98 & 5,16 & 2,02 & 6,48 & 2,34 \\
\hline $\mathrm{NO}_{2}$ & $\mathrm{mg} / \mathrm{L}$ & 0,003 & 0,006 & 0,003 & 0,005 & 0,004 & 0,005 & 0,004 & 0,006 & 0,005 & 0,009 \\
\hline $\mathrm{NO}_{3}$ & $\mathrm{mg} / \mathrm{L}$ & 1,73 & 1,03 & 0,98 & 0,55 & 0,87 & 0,62 & 1,14 & 0,41 & 1,53 & 0,86 \\
\hline $\mathrm{NH}_{4}$ & $\mathrm{mg} / \mathrm{L}$ & 0,04 & 0,03 & 0,03 & 0,02 & 0,06 & 0,07 & 0,14 & 0,51 & 0,04 & 0,03 \\
\hline SS & $\mathrm{mg} / \mathrm{L}$ & 12,21 & 27,64 & 7,80 & 21,82 & 10,22 & 20,78 & 16,82 & 35,81 & 18,09 & 33,08 \\
\hline $\mathrm{ST}$ & $\mathrm{mg} / \mathrm{L}$ & 25,66 & 31,77 & 17,24 & 22,25 & 17,66 & 20,31 & 25,89 & 35,89 & 29,26 & 32,54 \\
\hline SD & $\mathrm{mg} / \mathrm{L}$ & 13,45 & 18,27 & 9,43 & 5,46 & 7,94 & 6,06 & 9,50 & 8,98 & 11,20 & 6,65 \\
\hline DBO & $\mathrm{mg} / \mathrm{L} \mathrm{O}_{2}$ & 0,46 & 0,26 & 0,83 & 0,50 & 1,54 & 2,30 & 0,90 & 0,71 & 0,62 & 0,45 \\
\hline DQO & $\mathrm{mg} / \mathrm{L} \mathrm{O}_{2}$ & 4,21 & 2,23 & 4,05 & 2,03 & 4,26 & 3,01 & 4,53 & 3,31 & 4,23 & 2,36 \\
\hline $\mathrm{Ca}$ & ppm & 1,92 & 0,66 & 1,86 & 0,54 & 1,47 & 0,63 & 1,63 & 0,58 & 2,07 & 0,69 \\
\hline $\mathrm{Mg}$ & ppm & 0,35 & 0,10 & 0,25 & 0,12 & 0,24 & 0,12 & 0,28 & 0,15 & 0,35 & 0,17 \\
\hline $\mathrm{Fe}$ & ppm & 0,14 & 0,20 & 0,09 & 0,05 & 0,11 & 0,12 & 0,12 & 0,14 & 0,15 & 0,20 \\
\hline $\mathrm{Al}$ & ppm & 0,15 & 0,11 & 0,14 & 0,16 & 0,14 & 0,16 & 0,20 & 0,19 & 0,24 & 0,20 \\
\hline $\mathrm{Si}$ & ppm & 2,43 & 0,54 & 2,05 & 0,55 & 1,53 & 0,66 & 1,93 & 0,53 & 2,33 & 0,57 \\
\hline $\mathrm{P}$ & ppm & 0,12 & 0,18 & 0,07 & 0,08 & 0,06 & 0,05 & 0,06 & 0,05 & 0,06 & 0,05 \\
\hline $\mathrm{Na}$ & ppm & 0,51 & 0,17 & 0,64 & 0,22 & 0,61 & 0,17 & 0,66 & 0,25 & 0,52 & 0,17 \\
\hline $\mathrm{K}$ & ppm & 0,36 & 0,18 & 0,25 & 0,31 & 0,28 & 0,24 & 0,25 & 0,14 & 0,32 & 0,13 \\
\hline Vazão & $\mathrm{m}^{3} / \mathrm{s}$ & 1,855 & 1,478 & 0,212 & 0,112 & & & 0,288 & 0,149 & 2,109 & 1,763 \\
\hline
\end{tabular}

\section{Estatística}

De acordo com a PCA, os parâmetros se associaram em oito PCs identificando respostas ao uso e ocupação do solo na bacia, bem como a importância de cada na variação na qualidade de água. Assim, a PCA foi realizada sobre os dados padronizados da matriz de 24 linhas/parâmetros por 115 colunas/observações, no modo R. A extração procedeu-se segundo o critério de Kaiser, ${ }^{17}$ para extração de autovalores $>1$, e o critério Varimax, ${ }^{17}$ para a maximização e minimização dos maiores e menores autovalores, respectivamente (Tabela 2). Para efeitos de avaliação, foram considerados os autovalores maiores que $0,500 .^{6}$

As oito PCs juntas explicaram 70,88\% dos dados, sendo as duas primeiras responsáveis por cerca de $29 \%$ da variação dos dados. A PC1 explica $16,41 \%$ da variância total e os elementos $\mathrm{Ca}, \mathrm{Mg}$, $\mathrm{Al}$ e $\mathrm{Si}$, juntamente com a dureza $(\mathrm{Ca}$ e $\mathrm{Mg})$, melhor contribuem para essa componente. Condutividade, alcalinidade, nitrato, sólidos dissolvidos e K são as principais variáveis da PC2 (12,62\%). Na terceira $\mathrm{PC}(11,75 \%)$ os maiores pesos estão relacionados à amônia, sólidos suspensos, sólidos totais e DQO. A associação pH, oxigênio dissolvido e nitrito estão presentes na PC4 $(7,57 \%)$ e a PC5 $(6,02 \%$ da variância) contém os parâmetros temperatura e P. O Na é o único parâmetro na PC6, que explica 6,05\% da variação. A PC7 (5,52\%) possui um peso positivo da cor e a PC8 $(4,93 \%)$ o Fe.

Utilizando os dados da Tabela 2, escritos sob a forma de principais componentes, de modo a dar uma importância maior aos dados que efetivamente causam variação na qualidade de água, foi realizada a análise de agrupamento. A CA hierárquica reuniu os parâmetros mais semelhantes em três grupos (Figura 1) cuja significância de cada agrupamento é determinada através do critério (Dlink/Dmax) x100<60. ${ }^{1}$ Quanto menor a distância entre as variáveis, maior é a similaridade entre elas.

O Grupo A, correlacionável com a primeira principal componente, é formado por parâmetros indicadores de composição geoquímica de rochas e solos da bacia ( $\mathrm{Al}, \mathrm{Fe}, \mathrm{Mg}, \mathrm{Si}$ e $\mathrm{Ca}$ ), exceto para o fósforo, que está associado à atividade agrícola. $\mathrm{O}$ Grupo $\mathrm{C}(\mathrm{pH}$, oxigênio dissolvido, nitrito, temperatura, cor, sódio e demanda bioquímica de oxigênio) reúne os indicadores físico-químicos da qualidade de água. O Grupo B, formado pela condutividade, sólidos dissolvidos, alcalinidade, nitrato, turbidez, K, amônia, sólidos suspensos e sólidos totais (parâmetros da segunda e terceira componente principal) é um misto de indicadores geoquímicos e físico-químicos. Se desconsiderarmos o critério (Dlink/Dmax)x $100<60$, o grupo B reflete mais a qualidade de água, do que a geoquímica. 
Tabela 2. Pesos das 24 variáveis nas 8 principais componentes rotacionadas mais significantes para os 5 pontos de estudo no Córrego Cedro e Ribeirão do Gama

\begin{tabular}{|c|c|c|c|c|c|c|c|c|}
\hline & PC1 & $\mathrm{PC} 2$ & $\mathrm{PC} 3$ & PC4 & PC5 & PC6 & PC7 & PC8 \\
\hline $\mathrm{PH}$ & $-0,055$ & 0,148 & $-0,213$ & 0,763 & 0,031 & 0,275 & $-0,032$ & $-0,059$ \\
\hline TEMP & $-0,012$ & 0,002 & 0,103 & 0,193 & 0,756 & 0,234 & 0,027 & $-0,066$ \\
\hline COND & 0,205 & $\mathbf{0 , 8 2 9}$ & $-0,056$ & $-0,164$ & 0,111 & 0,057 & 0,069 & $-0,106$ \\
\hline OD & $-0,038$ & $-0,005$ & 0,117 & 0,775 & 0,227 & $-0,083$ & 0,167 & 0,221 \\
\hline ALCA & 0,098 & 0,604 & 0,185 & 0,152 & $-0,200$ & 0,016 & $-0,099$ & $-0,346$ \\
\hline TUR & $-0,195$ & 0,406 & 0,316 & 0,005 & $-0,156$ & $-0,264$ & 0,339 & 0,308 \\
\hline $\mathrm{COR}$ & $-0,032$ & 0,018 & $-0,123$ & 0,021 & 0,078 & 0,227 & $\mathbf{0 , 7 8 8}$ & 0,007 \\
\hline DUR & 0,929 & 0,123 & 0,000 & $-0,090$ & $-0,056$ & $-0,005$ & 0,095 & 0,035 \\
\hline NO2 & $-0,352$ & $-0,069$ & $-0,046$ & $\mathbf{0 , 5 9 7}$ & $-0,400$ & $-0,243$ & $-0,047$ & $-0,100$ \\
\hline NO3 & 0,060 & 0,663 & 0,294 & 0,279 & 0,062 & 0,093 & $-0,165$ & 0,153 \\
\hline NH4 & 0,065 & $-0,088$ & $\mathbf{0 , 5 0 7}$ & $-0,135$ & 0,009 & $-0,357$ & 0,105 & 0,015 \\
\hline SS & 0,025 & 0,021 & $\mathbf{0 , 9 4 7}$ & 0,004 & 0,024 & 0,019 & $-0,195$ & $-0,030$ \\
\hline ST & 0,071 & 0,311 & $\mathbf{0 , 8 8 4}$ & 0,034 & 0,024 & 0,044 & $-0,167$ & $-0,019$ \\
\hline SD & 0,137 & $\mathbf{0 , 8 1 7}$ & $-0,042$ & 0,066 & 0,009 & 0,058 & 0,057 & 0,023 \\
\hline DBO & $-0,385$ & $-0,116$ & $-0,074$ & $-0,195$ & 0,073 & 0,262 & $-0,455$ & 0,131 \\
\hline DQO & $-0,155$ & 0,191 & 0,679 & $-0,041$ & 0,144 & 0,184 & 0,279 & $-0,031$ \\
\hline CA & 0,871 & 0,116 & $-0,044$ & $-0,114$ & $-0,012$ & $-0,012$ & 0,149 & $-0,025$ \\
\hline MG & 0,873 & 0,101 & 0,119 & 0,021 & $-0,145$ & 0,009 & $-0,079$ & 0,142 \\
\hline FE & 0,212 & 0,042 & $-0,040$ & 0,091 & $-0,036$ & 0,092 & $-0,035$ & 0,816 \\
\hline $\mathrm{AL}$ & 0,541 & $-0,141$ & $-0,037$ & 0,022 & $-0,377$ & 0,064 & $-0,179$ & 0,313 \\
\hline SI & 0,856 & 0,138 & $-0,048$ & $-0,080$ & 0,085 & $-0,053$ & $-0,102$ & 0,033 \\
\hline $\mathrm{P}$ & 0,240 & $-0,046$ & $-0,029$ & 0,082 & $-0,604$ & 0,354 & 0,012 & $-0,050$ \\
\hline NA & $-0,056$ & 0,046 & 0,076 & 0,011 & 0,030 & $\mathbf{0 , 8 5 4}$ & 0,155 & 0,090 \\
\hline $\mathrm{K}$ & 0,024 & 0,663 & 0,282 & $-0,069$ & 0,083 & $-0,130$ & 0,210 & 0,222 \\
\hline Eingevalue & 3,94 & 3,03 & 2,82 & 1,82 & 1,45 & 1,45 & 1,32 & 1,18 \\
\hline$\%$ Variance & 16,41 & 12,62 & 11,75 & 7,57 & 6,02 & 6,05 & 5,52 & 4,93 \\
\hline \% Cum. Var. & 16,41 & 29,03 & 40,78 & 48,36 & 54,38 & 60,43 & 65,95 & 70,88 \\
\hline
\end{tabular}

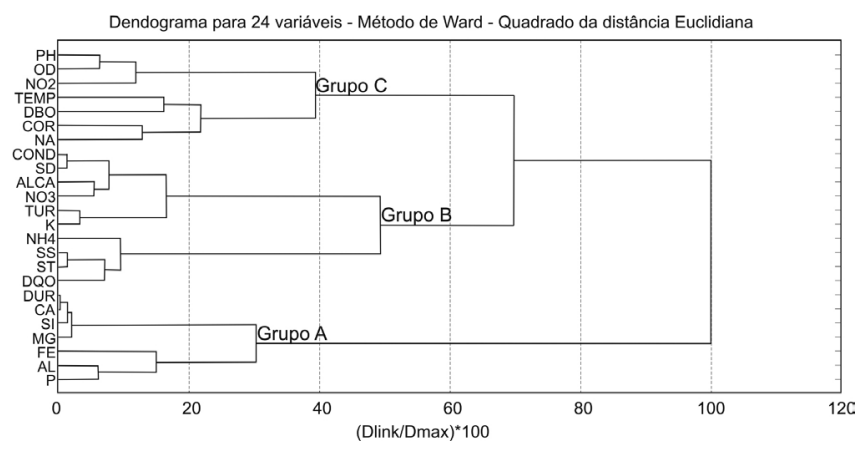

Figura 1. Dendograma mostrando o agrupamento das variáveis no Córrego Cedro e Ribeirão do Gama

A CA não-hierárquica, k-médias, foi realizada sobre os pesos de cada observação (modo Q) nas oito principais componentes. O método não hierárquico tem a vantagem de exigir a quantidade de grupos que se deseja diferenciar. A idéia principal do estudo é diferenciar do "comportamento" normal das águas, as observações anômalas, ou seja, dois grupos (Figura 2).
A partir dos resultados da análise agrupamento não-hierárquico foram constatadas duas condições no comportamento dos parâmetros avaliados. O grupo 1 é o comportamento médio ou background dos rios em estudo, já o grupo 2 é a condição anômala. Essa condição anômala foi detectada nos meses de março e abril de 2005 nos pontos 1, 2, 4 e 5, nos meses de janeiro e fevereiro de 2005 no ponto 3 e em junho de 2004 no ponto 5. Essas observações contêm um aumento expressivo nos valores de sólidos suspensos, sólidos totais e DQO e, em menor intensidade, em alcalinidade, nitrato e amônia, na sua maioria em período chuvoso.

A classificação não-hierárquica k-médias separou as observações em dois grupos bem distintos entre si. Com a análise discriminante foi possível obter uma função que diferencie esses grupos (variável independente) a partir dos parâmetros (variáveis dependentes). Além da função discriminante, a DA verificou se as observações foram alocadas corretamente pela CA. Segundo a DA, K-médias alocou corretamente $100 \%$ das observações nos grupos 1 e 2, tanto pelo modo standard quanto pelo modo stepwise.

Uma função discriminante foi gerada para os dois modos de análise. Na Tabela 3 são apresentados os pesos de cada variável dependente para cada função discriminante, de cada modo, neces- 
sários para o cálculo do escore de cada observação. A DA no modo stepwise forneceu apenas quatro parâmetros, estatisticamente mais significantes para discriminar as águas impactadas das não impactadas: nitrato, amônia, sólidos suspensos e Al. O índice discriminante calculado para o modo standard é 4,1684 e para o modo stepwise, igual a 3,8128. Isso significa que, após aplicar os resultados da análise de qualidade de água na função discriminante relacionados na Tabela 3, o resultado deve ser comparado com o índice discriminante. $\mathrm{O}$ resultado sendo maior que o índice discriminante indica água impactada pelo uso e ocupação do solo; sendo menor, indica que a água não estaria impactada.

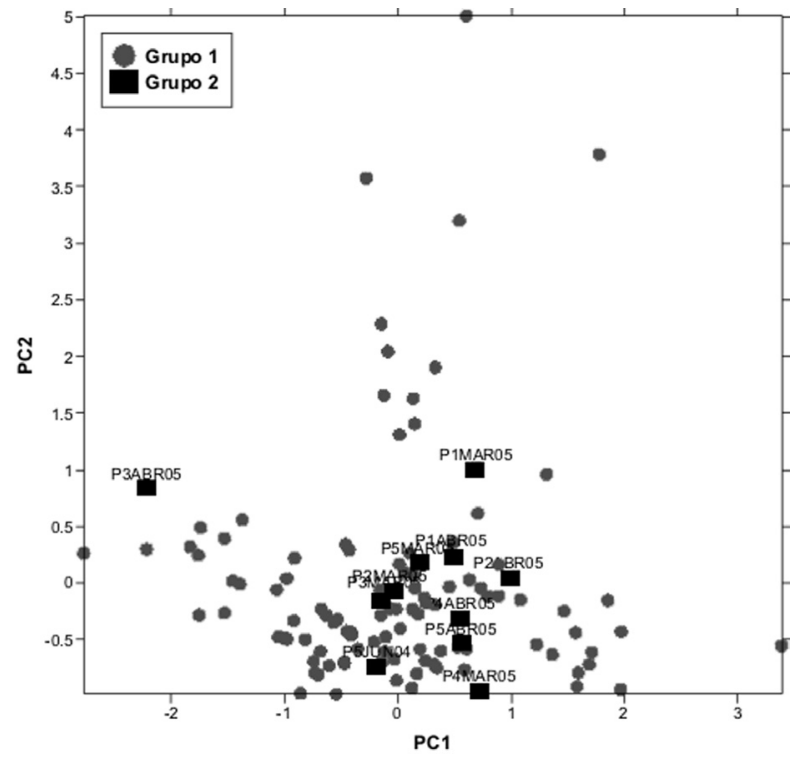

Figura 2. Gráfico de espalhamento dos pesos das observações nas duas primeiras principais componentes. As observações nomeadas são as que diferem do padrão normal, segundo o método k-médias de agrupamento

\section{Interpretação}

A associação entre parâmetros $\mathrm{Ca}, \mathrm{Mg}, \mathrm{Al}$ e Si, juntamente com a dureza (Ca e $\mathrm{Mg}$ ), é responsável pela maior variação na composição da água nos dois corpos hídricos estudados. Esse conjunto de variáveis aponta para uma origem comum, nos minerais presentes nos solos (Al e $\mathrm{Si}$ ) do Distrito Federal e a composição de materiais usados na construção civil (Ca e $\mathrm{Mg}$ ), ou seja, há um aporte de componentes químicos que denunciam a ausência de vegetação como cobertura do solo, por vez, substituída por habitações e obras de infraestrutura. Nesse contexto se encaixam a expansão do SMPW (novas habitações e pavimentação de vias), sem o devido manejo do solo, a construção da segunda pista do Aeroporto Internacional de Brasília e o NRVB. Os gráficos da Figura 3 mostram o aumento da concentração do Ca e Si ao longo do tempo, crescente, comprovando a expansão habitacional e de infraestrutura na bacia.

Confrontando a concentração do elemento e a vazão obtida no período para as duas drenagens estudadas, há uma dispersão dos valores de concentração em vazões baixas, as mais amostradas. A diminuição das concentrações em função do aumento da vazão está ligada às precipitações pluviométricas, que carreiam substâncias em função do escoamento superficial. Nesse caso o aumento da vazão não implica em aumento de concentração, indicando origem pontual e constante para os elementos. A dispersão das observações, em baixas vazões, está ligada às fontes pontuais e constantes de $\mathrm{Ca} \mathrm{e}$ $\mathrm{Si}$, provenientes de materiais de construção, construção da segunda pista e erosão do solo, cuja baixa disponibilidade de água faz as concentrações se elevarem.
Tabela 3. Pesos para classificação por análise discriminante da qualidade de água do Córrego Cedro e Ribeirão do Gama

\begin{tabular}{|c|c|c|}
\hline Parâmetros & $\begin{array}{c}\text { Standard } \\
\text { FD }\end{array}$ & $\begin{array}{c}\text { Stepwise } \\
\text { FD }\end{array}$ \\
\hline $\mathrm{pH}$ & $-0,158$ & - \\
\hline Temp & 0,047 & - \\
\hline Cond & $-0,009$ & - \\
\hline OD & $-0,197$ & - \\
\hline Alca & 0,024 & - \\
\hline Tur & $-0,011$ & - \\
\hline Cor & $-0,002$ & - \\
\hline Dur & 0,280 & - \\
\hline $\mathrm{NO} 2$ & 22,962 & - \\
\hline NO3 & $-0,339$ & $-0,331$ \\
\hline NH4 & $-2,298$ & $-1,705$ \\
\hline SS & 0,309 & 0,113 \\
\hline ST & $-0,195$ & - \\
\hline SD & 0,200 & - \\
\hline DBO & 0,360 & - \\
\hline DQO & 0,071 & - \\
\hline $\mathrm{Ca}$ & $-0,727$ & - \\
\hline $\mathrm{Mg}$ & $-1,027$ & - \\
\hline $\mathrm{Fe}$ & 1,188 & - \\
\hline $\mathrm{Al}$ & 1,293 & 1,434 \\
\hline $\mathrm{Si}$ & 0,132 & - \\
\hline $\mathrm{P}$ & 0,403 & - \\
\hline $\mathrm{Na}$ & 0,255 & - \\
\hline K & 0,526 & - \\
\hline Constante & $-1,305$ & $-1,177$ \\
\hline
\end{tabular}

Para os demais elementos, $\mathrm{Mg}, \mathrm{Fe}$ e $\mathrm{Al}$, a mesma lógica acima é aplicada. Para o $\mathrm{Fe}$ e $\mathrm{Al}$, a dispersão é mínima uma vez que esses elementos estão associados apenas à erosão do solo. Já o Mg, com maior dispersão nos dois corpos hídricos, se relaciona também aos insumos agrícolas utilizados no cultivo de hortifrutigranjeiros.

Secundariamente, temos alguns parâmetros que refletem o aporte de íons nos rios e outros que detectam a entrada desses materiais. A associação de condutividade, alcalinidade, nitrato, sólidos dissolvidos e K impacta mais a composição das águas dos rios do que amônia, sólidos suspensos, sólidos totais e DQO, e também pelo $\mathrm{pH}$, oxigênio dissolvido e nitrito. Nitrato e K têm origem associada ao NRVB, um aglomerado de agricultores produtores de hortifrutigranjeiros, que usam fertilizantes como insumos. A oxidação de compostos nitrogenados se dá quimicamente e a oxidação não biológica permite afirmar a ausência parcial de poluição por esgoto. Na e P são macro e micronutrientes de fertilizantes e o Fe é responsável pela cor na água.

De maneira geral, é possível associar as PCs de números 1, 2, 7 e 8 com a influência predominante da geoquímica de rochas e solos na composição da água no Córrego Cedro e Ribeirão do Gama. As demais principais componentes demonstram o comportamento da água em função do aporte de materiais não geológicos e matéria orgânica, sugerindo uma maior contribuição do agente antrópico ao natural. Segundo a PCA, os parâmetros DBO e turbidez não foram 

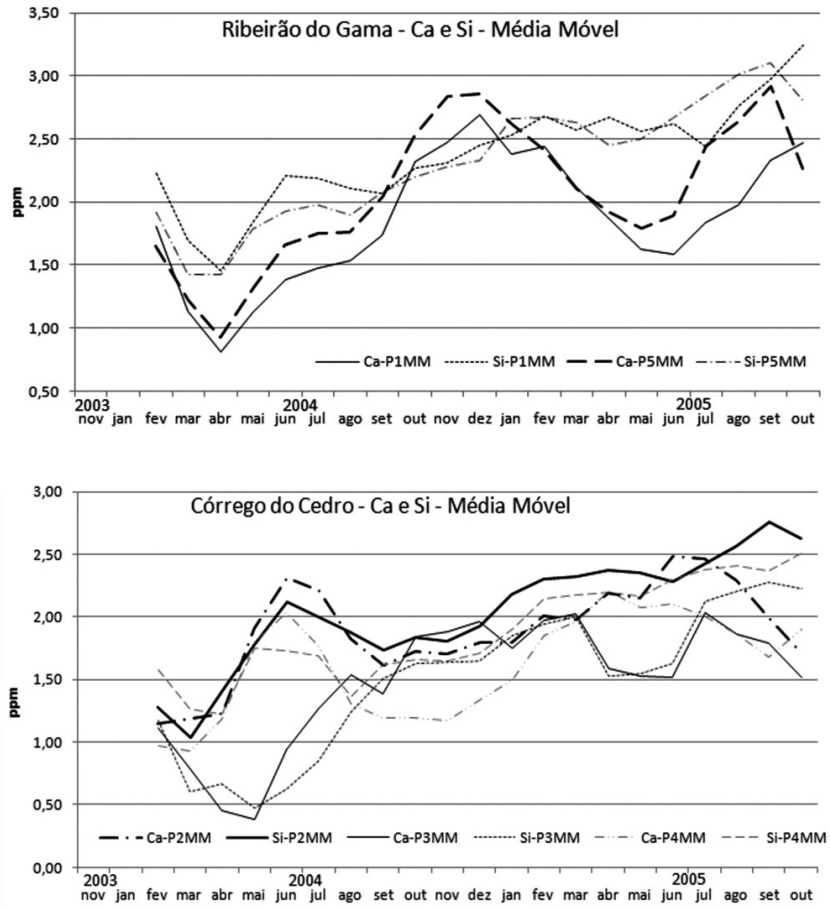

Figura 3. Gráfico de média móvel para o Ribeirão Gama e Córrego do Cedro para Ca e Si ao longo do período de coleta

significantes para alguma variação na qualidade de água. $\mathrm{O}$ fato da DBO não ter atingido valores diferenciados, não tira a importância de ser um dos melhores indicadores de qualidade da água.

Das 115 observações, 11 se destacaram por apresentarem características diferentes, em função da forma como os parâmetros variaram. $\mathrm{O}$ agrupamento dessas observações foi realizado pela CA não-hierárquica, confirmada pela DA. Essas características são interpretadas como consequência do uso e ocupação do solo na bacia, principalmente na época chuvosa, onde os processos atuantes são aumentados. A Figura 4 mostra a diferença das águas não-impactadas (Grupo 1) e impactadas (Grupo 2).

$\mathrm{O}$ aumento do aporte de materiais sólidos na bacia tem origem orgânica e inorgânica. Os parâmetros inorgânicos anômalos, Ca e Mg têm associação com materiais usados na construção civil, uma vez que a geologia da Bacia do Lago Paranoá não possui rochas carbonáticas ou cálcio-magnesianas, o Si aliado ao Al e K denuncia a erosão dos solos, pois constituem argilominerais presentes no solo do DF, como a ilita e a caolinita. ${ }^{18}$ Quanto aos parâmetros orgânicos, no Córrego Cedro, o nitrato tem origem no fenômeno da subida do lençol freático com a interação do solo hidromórfico. Este aspecto mostra uma característica local e demonstra que em algumas situações o nitrato pode se associar a origens diferentes da condição antrópica, demonstrando a importância do conhecimento geoquímico/geomorfológico, nas interpretações de qualidade de água em bacias hidrográficas.

A amônia está relacionada com o lançamento de esgoto/lixo doméstico no ponto 4, pela população próxima, que não conta com os serviços de saneamento básico. No Ribeirão do Gama, os compostos nitrogenados associados ao $\mathrm{Ca}, \mathrm{Mg}$ e $\mathrm{K}$ sugerem poluição por insumos agrícolas do Núcleo Rural Vargem Bonita. A entrada anômala desses sólidos é acompanhada pela variação dos parâmetros físico-químicos, como condutividade, alcalinidade e DQO, ou seja, nessa região a atividade agrícola, além de desnudar o horizonte superior dos solos, não aplica os insumos agrícolas de maneira sustentável.

Quanto ao modelo proposto, utilizando a DA, este deve ser usado com restrições numa avaliação de qualidade de água. Para fins de
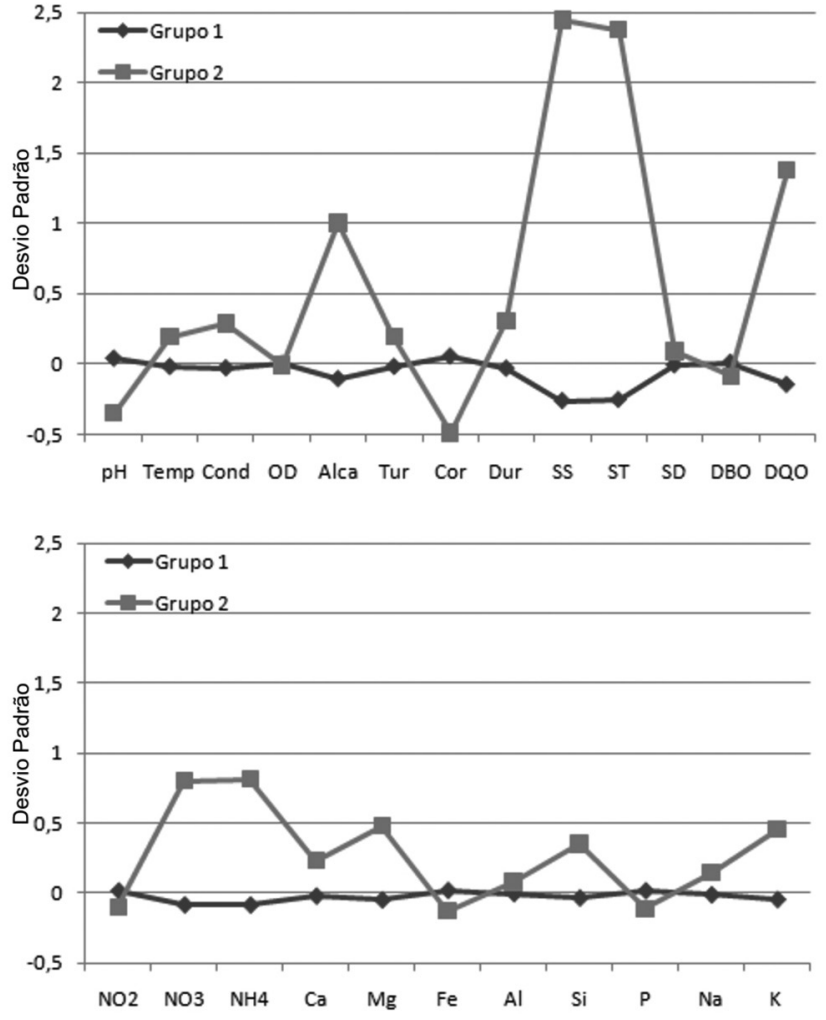

Figura 4. Gráfico resultante da padronização das médias para os parâmetros físico-químicos, compostos nitrogenados e elementos, mostrando as diferenças entre os 2 grupos resultantes da análise agrupamento não-hierárquico

monitoramento, apenas para diferenciar entre água impactada ou não, é aplicável. Se o usuário do modelo quer identificar a origem e o tipo de impacto que ocorre na água, este é um indicador de quando uma análise de qualidade de água, usando uma gama maior de parâmetros, se torna necessária. Sólidos suspensos e Al, juntos, não são bons indicadores da proveniência de materiais, o nitrato pode ter dupla proveniência (orgânica natural e antrópica) cuja distinção é determinada pela amônia que, na maioria das situações, estará indicando contaminação por esgoto doméstico.

Segundo a PCA, dois parâmetros são insignificantes na variação dos dados: a DBO, usada como indicadora de poluição e substituível por amônia e OD e, a turbidez. Dureza e sólidos suspensos/sólidos dissolvidos são análogos ao $\mathrm{Ca} / \mathrm{Mg}$ e sólidos dissolvidos, ou seja, redundantes. É importante ressaltar que a substituição da DBO pela amônia deve ser avaliada de forma a considerar a ecotoxidade da mesma e que, em casos específicos onde sua concentração estiver acima da normalidade, devem ser acrescentadas as determinações de DBO no programa de avaliação da composição e qualidade da água.

Os resultados demonstraram que toda alteração na ocupação de uma bacia é refletida na qualidade de água dos corpos hídricos que drenam a área. A análise da qualidade de água gera muitos dados, sendo indispensável o uso de métodos de avaliação de dados. Os métodos estatísticos multivariados oferecem a possibilidade de reduzir essas informações e selecionar os aspectos mais significativos. O modelo proposto nesse trabalho permitiu associar as informações da análise físico-química de água com a ocupação do solo, visíveis nas pesquisas em campo e imagens de satélite. Além disso, a estatística possibilitou separar quais parâmetros são indicadores de qualidade de água relacionados à ocupação humana. A equação reduzida, proposta para discriminar água impactada da não-impactada, apontou parâmetros incompatíveis com o uso e ocupação do solo na bacia. Essa questão 
não invalida o modelo proposto, porém sugere que, quando a equação apontar água impactada, novas análises devam ser feitas usando maior quantidade de parâmetros de investigação. $\mathrm{O}$ fato das coletas de água terem sido iniciadas após o desmatamento da área, onde a segunda pista do aeroporto seria construída, pode ter influenciado na criação do modelo, uma vez que águas menos impactadas não foram incorporadas na análise estatística e na avaliação da qualidade de água.

\section{CONCLUSÃO}

Neste estudo foram avaliados diversos métodos estatísticos multivariados para avaliação da qualidade de água na Bacia do Gama. O uso da estatística permitiu avaliar a qualidade de água e gerar um modelo a partir da água impactada/não-impactada. A PCA reduziu a matriz de dados de $24 \times 115$ para $24 \times 8$, ou seja, foram extraídas oito PCs e permitiu detectar a origem dos materiais transportados pelas drenagens, associados à construção civil, aos minerais presentes no solo e aos fertilizantes.

A CA hierárquico permitiu verificar a similaridade entre as variáveis estudadas, agrupando-as em três grupos: indicadores geoquímicos de rochas e solos, de qualidade de água e um misto dos dois indicadores. Já a CA não-hierárquico (K-médias) separou as observações em dois grupos, que refletiam duas condições de qualidade de água: o background, ou água não-impactada e a anômala, água impactada pelo uso e ocupação do solo.

A DA, além de fornecer o modelo matemático para a distinção das duas condições de qualidade de água, confirmou em $100 \%$ o agrupamento das observações realizado pelo k-médias. O modelo stepwise gerou a equação selecionando os melhores parâmetros para o cálculo da mesma: nitrato, amônia, sólidos suspensos e Al.

Apesar do estudo demonstrar a utilidade dos métodos estatísticos na avaliação de qualidade de água, esses métodos por si só não são suficientes na interpretação dos dados. O conhecimento acerca da geologia local e do uso e ocupação do solo na bacia são informações determinantes na busca das fontes causadoras de impacto na qualidade de água. Além disso, os autores frisam que a equação discriminante deve ser usada como acessória a uma futura avaliação, sobretudo o modo stepwise. Por exemplo, numa nova coleta de água as determinações poderiam se restringir aos parâmetros do modo stepwise, a equação apontando impacto, novas determinações seriam necessárias para a localização da origem. Os métodos estatísticos reduzem a quantidade de parâmetros baseados apenas na variabilidade dos dados, descartando a importância teórica e prática deles. Numa provável continuação da avaliação de qualidade de água na Bacia do Gama, a quantificação de nitrato, amônia, sólidos suspensos e Al, sozinhos, não apontariam a causa na mudança da qualidade de água, mas se aplicados à equação discriminante, resultando em água impactada, mais parâmetros deverão ser determinados com o objetivo de mapear a fonte do impacto

\section{MATERIAL SUPLEMENTAR}

Disponível em http://quimicanova.sbq.org.br, na forma de arquivo .PDF, com acesso livre.

\section{AGRADECIMENTOS}

À CAPES (Coordenação de Aperfeiçoamento de Pessoal de Nível Superior), pela concessão de bolsa de mestrado, à INFRAERO, pelo acesso ao sítio aeroportuário, a GeoLógica, pelo apoio às visitas em campo e ao $\mathrm{CNPq}$, pelo apoio às pesquisas.

\section{REFERÊNCIAS}

1. Shresta, S.; Kazama, F.; Environ. Modelling Software 2007, 22, 464; Singh, K. P.; Malik, A.; Sinha, S.; Anal. Chim. Acta 2005, 538, 355.

2. Pinelli, M. P.; Boaventura, G. R.; Santos, R. V.; $3^{\text {rd International }}$ Symposium Environmental Geochemistry in Tropical Countries, Nova Friburgo, Brasil, 1999.

3. Do Carmo, M. S.; Boaventura, G. R.; Oliveira, E. C.; Quim. Nova 2005, 28,555 .

4. Boaventura, G. R.; Freitas, A. L. S.; Water, Air, Soil Pollut. 2006, 171, 135 .

5. Lima, J. E. F. W.; Recursos Hídricos no Brasil e no Mundo, $1^{\mathrm{a}}$ ed., Embrapa Cerrados: Planaltina, 2001.

6. Hair, J. F.; Multivariate data analysis, $5^{\text {th }}$ ed., Prentice Hall: New Jersey, 1998.

7. Moita Neto, J. M.; Moita, G. C.; Quim. Nova 1998, 21, 467.

8. Prado, P. I.; Lewinsohn, T. M.; Do Carmo, R. L.; Hogan, D. J.; Amb. Soc. 2002, 5, 1; Chen, K.; Jiao, J. J.; Huang, J.; Huang, R.; Environ. Pollut. 2007, 147, 771.

9. Voudouris, K.; Panagopoulos, A.; Koumantakis, J.; Natural Resources Research 2000, 9, 135; Regunath, R.; Sreedhara Murthy, T. R.; Raghavan, B. R.; Water Res. 2002, 36, 2437; Jayakumar, R.; Siraz, L.; Environ. Geol. 1997, 31, 174.

10. IEMA/DF; SEMATEC/DF; Inventário hidrogeológico e dos recursos hídricos superficiais do Distrito Federal, UnB: Brasília, 1998.

11. Ribeiro, J. F.; Walter, B. M. T. Em Cerrado: Ambiente e Flora; Almeida, S. P.; Sano, S. M., eds.; EMBRAPA: Planaltina, 1998.

12. APHA-AWWA-WPCF; Standard Methods for Examination of Water and Wastewater, $20^{\text {th }}$ ed.; Washington, 1999.

13. Petersen, W.; Bertino, L.; Callies, U.; Zorita E.; Ecological Modelling 2001, 138, 193; Fernandes, P. G.; Carreira, P.; da Silva, M. O.; Math. Geology 2006, 38,765; Strapasson, E.; Vencovsky, R.; Batista, L. A. R.; Revista Bras. Zootecnia 2000, 29, 373.

14. Vega, M.; Pardo, R.; Barrado, E.; Debán, L.; Water Res. 1998, 32, 3581.

15. Beauchaine, T. P.; Beauchaine III, R. J.; Psychological Methods 2002, $7,245$.

16. Davis, J. C.; Statistics and data analysis in geology, $3^{\text {rd }}$ ed.; Wiley: New York, 2002.

17. Kaiser, H. F.; Psychometrika 1958, 23, 187.

18. Maia, P. D.; Guimarães, E. M.; Moreira, R. C. A.; Boaventura, G. R.; Rev. Bras. de Geoc. 2005, 35, 535; Moreira, R. C. A.; Boaventura, G. R.; Quim. Nova 2003, 26, 812 . 
A QUALIDADE DE ÁGUA COMO INDICADOR DE USO E OCUPAÇÃO DO SOLO: BACIA DO GAMA DISTRITO FEDERAL

Luiz Henrique Amorim Moura*, Geraldo Resende Boaventura e Marcelo Pedrosa Pinelli Instituto de Geociências, Universidade de Brasília, 70910-900 Brasília - DF, Brasil

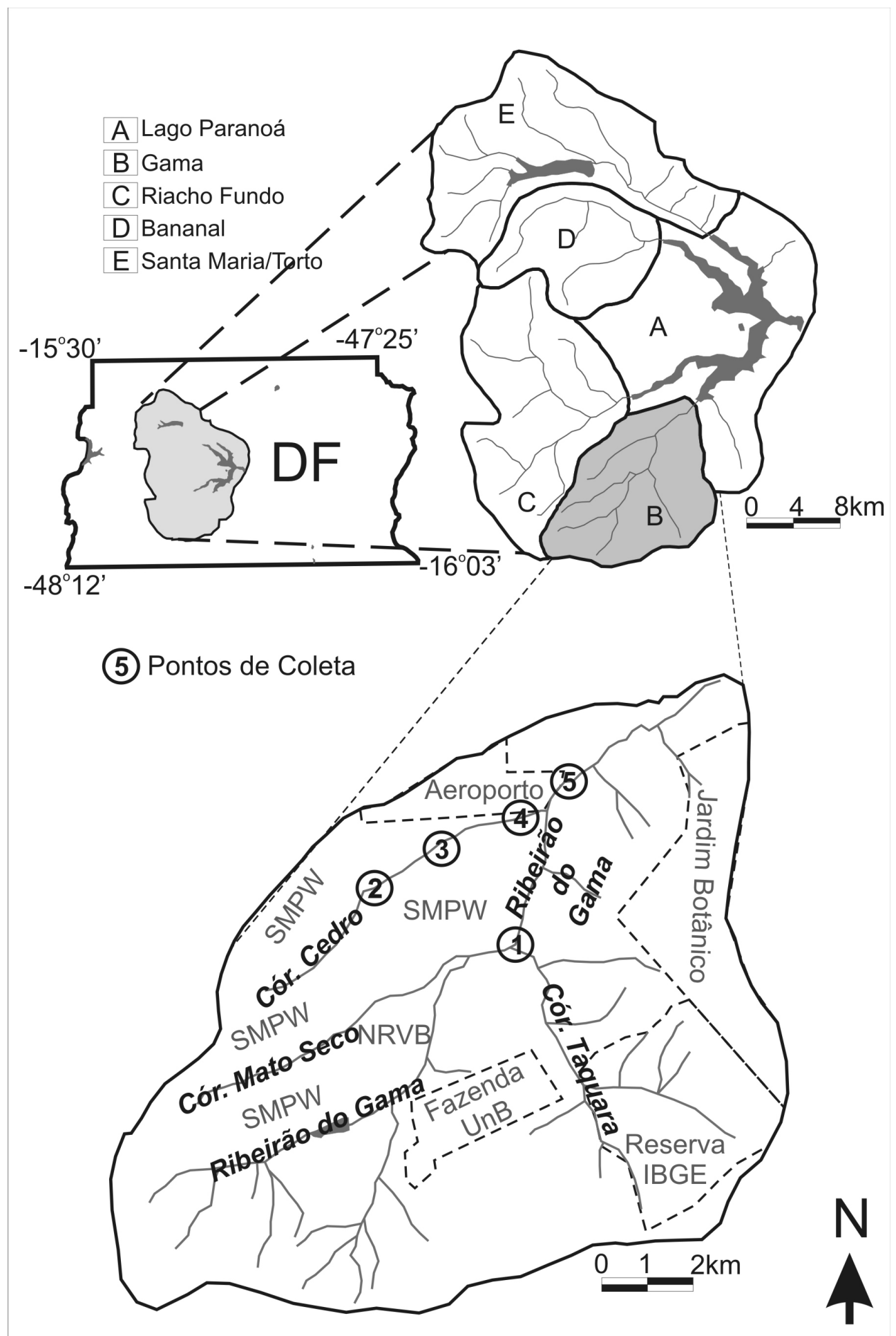

Figura 1S. Localização da Bacia do Gama, bacias vizinhas e os pontos de coleta, com classificação simplificada de uso e ocupação do solo 

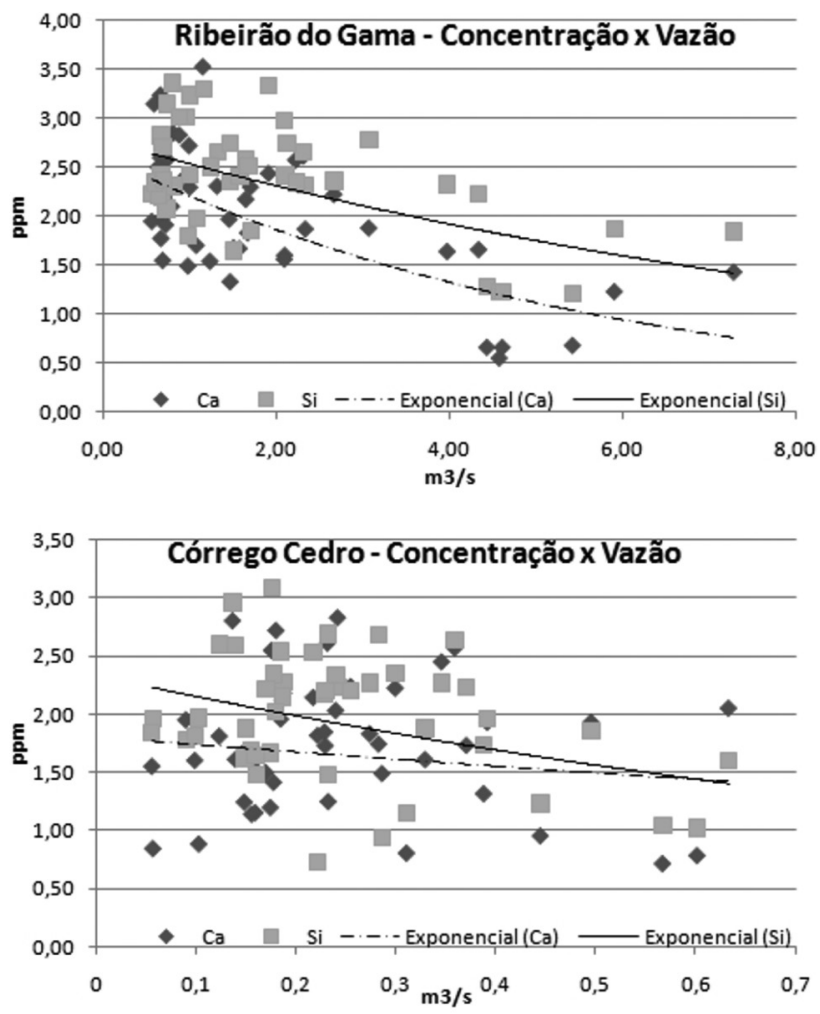

Figura 2S. Dispersão da relação concentração (Ca e Si) e vazão no Córrego Cedro e Ribeirão do Gama
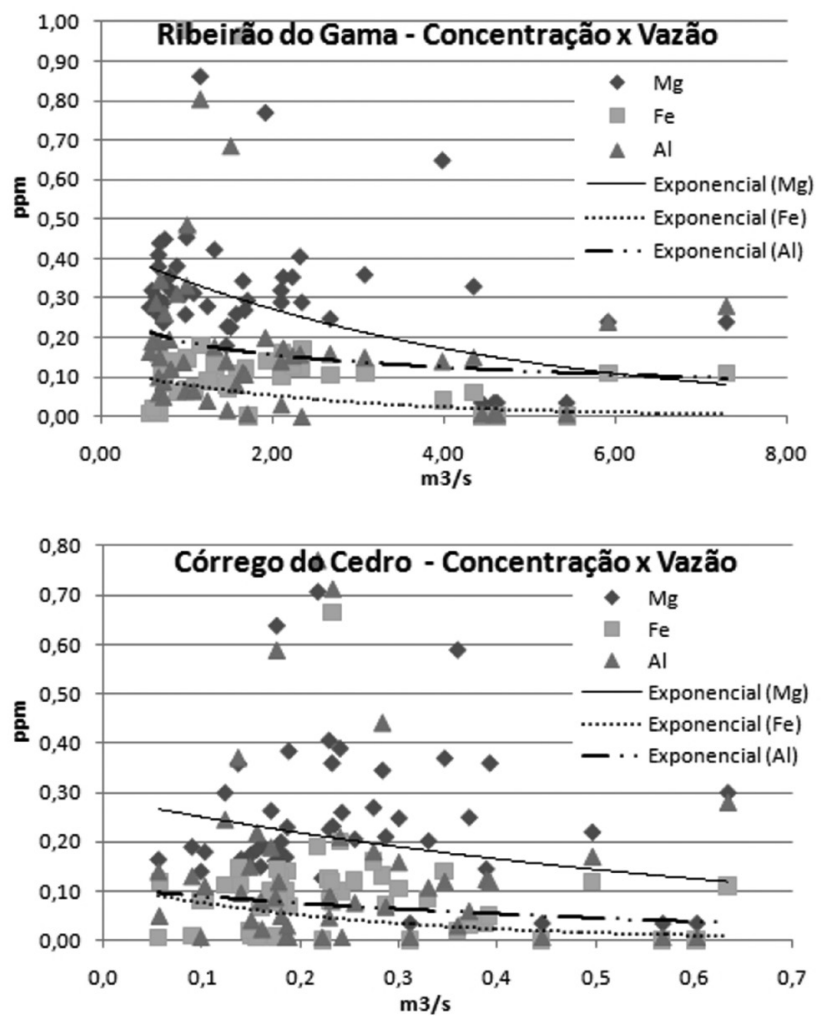

Figura $3 \mathrm{~S}$ - Dispersão da relação concentração $(\mathrm{Mg}$, Fe e Al) e vazão no Córrego Cedro e Ribeirão do Gama
Tabela 1S. Localização dos pontos de coleta no Ribeirão do Gama e Córrego do Cedro

\begin{tabular}{ccc}
\hline Pontos de Coleta & \multicolumn{2}{c}{ Coordenadas UTM (Zona 23L, m) } \\
\hline $\mathbf{1}$ & Leste & Norte \\
$\mathbf{2}$ & 188.228 & 8.239 .296 \\
$\mathbf{3}$ & 185.075 & 8.240 .338 \\
$\mathbf{4}$ & 186.808 & 8.241 .540 \\
$\mathbf{5}$ & 188.474 & 8.241 .995 \\
\end{tabular}

Tabela 2S. Tabela com os valores médios e o desvio padrão das observações agrupadas segundo o método não hierárquico k-médias

\begin{tabular}{|c|c|c|c|c|c|}
\hline & \multirow[b]{2}{*}{ Unidade } & \multicolumn{2}{|c|}{ Grupo $1(n=104)$} & \multicolumn{2}{|c|}{ Grupo $2(n=11)$} \\
\hline & & Média & Desvio & Média & Desvio \\
\hline $\mathrm{pH}$ & - & 6,03 & 0,55 & 5,81 & 0,66 \\
\hline Temp & ${ }^{\circ} \mathrm{C}$ & 20,66 & 1,38 & 20,95 & 0,99 \\
\hline Cond & $\mu \mathrm{S} / \mathrm{cm}$ & 18,7 & 13,7 & 23,2 & 12,8 \\
\hline OD & $\mathrm{mg} / \mathrm{L}$ & 6,44 & 1,07 & 6,43 & 0,78 \\
\hline Alca & $\mathrm{mg} / \mathrm{L} \mathrm{CaCO}{ }_{3}$ & 11,0 & 4,7 & 16,9 & 7,6 \\
\hline Tur & uT & 11,1 & 9,6 & 13,1 & 5,4 \\
\hline Cor & $\mathrm{uH}$ & 12,9 & 13,5 & 5,7 & 6,5 \\
\hline Dur & $\mathrm{mg} / \mathrm{L} \mathrm{CaCO}{ }_{3}$ & 5,53 & 2,21 & 6,26 & 0,96 \\
\hline $\mathrm{NO}_{2}$ & $\mathrm{mg} / \mathrm{L}$ & 0,004 & 0,006 & 0,003 & 0,008 \\
\hline $\mathrm{NO}_{3}$ & $\mathrm{mg} / \mathrm{L}$ & 1,18 & 0,75 & 1,88 & 0,92 \\
\hline $\mathrm{NH}_{4}$ & $\mathrm{mg} / \mathrm{L}$ & 0,04 & 0,04 & 0,25 & 0,74 \\
\hline SS & $\mathrm{mg} / \mathrm{L}$ & 5,27 & 10,14 & 80,99 & 44,89 \\
\hline ST & $\mathrm{mg} / \mathrm{L}$ & 15,40 & 14,57 & 91,35 & 38,27 \\
\hline SD & $\mathrm{mg} / \mathrm{L}$ & 10,25 & 10,64 & 11,27 & 7,10 \\
\hline DBO & $\mathrm{mg} / \mathrm{L} \mathrm{O}_{2}$ & 0,88 & 1,23 & 0,77 & 0,53 \\
\hline DQO & $\mathrm{mg} / \mathrm{L} \mathrm{O}_{2}$ & 3,83 & 2,15 & 7,64 & 2,96 \\
\hline $\mathrm{Ca}$ & ppm & 1,78 & 0,67 & 1,94 & 0,35 \\
\hline $\mathrm{Mg}$ & ppm & 0,26 & 0,15 & 0,34 & 0,11 \\
\hline $\mathrm{Fe}$ & ppm & 0,10 & 0,15 & 0,08 & 0,04 \\
\hline $\mathrm{Al}$ & ppm & 0,15 & 0,17 & 0,16 & 0,18 \\
\hline $\mathrm{Si}$ & $\mathrm{ppm}$ & 2,04 & 0,66 & 2,29 & 0,40 \\
\hline $\mathrm{P}$ & ppm & 0,06 & 0,10 & 0,05 & 0,03 \\
\hline $\mathrm{Na}$ & ppm & 0,58 & 0,21 & 0,62 & 0,20 \\
\hline K & ppm & 0,28 & 0,20 & 0,38 & 0,22 \\
\hline
\end{tabular}

